\title{
Effect of Matrix onto Oxidation of Metallic Nanoparticles in Metal-Insulator Nanocomposite Films
}

\author{
J.A. FEDOTOVA \\ NC PHEP Belarusian State University, 220088 Minsk, Belarus
}

\begin{abstract}
Paper reports the results of X-ray diffraction, X-ray absorption spectroscopy and the Mössbauer spectroscopy of metal-insulator films sintered in $\mathrm{Ar}+\mathrm{O}$ atmosphere evidencing the difference in oxidation of FeCoZr nanoparticles embedded into $\mathrm{Al}_{2} \mathrm{O}_{3}$ and $\mathrm{Pb}(\mathrm{ZrTi}) \mathrm{O}_{3}$ matrixes. It is proved that $\mathrm{Al}_{2} \mathrm{O}_{3}$ matrix with high resistance to oxidation favors the formation of nanoparticles with "metal core-oxide shell" structure, while fully oxidized nanoparticles are observed inside $\mathrm{Pb}(\mathrm{ZrTi}) \mathrm{O}_{3}$ matrix.
\end{abstract}

DOI: $10.12693 /$ APhysPolA.125.1418

PACS: 73.40.Gk, 73.40.Rw, 73.63.Bd, 62.23.Pq, 68.37.Lp, 68.37.Og

\section{Introduction}

Synthesis of nanoparticles (NPs) with "metallic coreoxide shell" structure in nanocomposite metal-insulator films $\left(\mathrm{M}_{x}-\mathrm{I}_{100-x}, 20<x<80\right.$ at.\%) is an effective technique to stabilize their granular structure at $x>50$, i.e. to keep well-separated NPs, because oxide shells impede agglomeration of metallic cores and increase homogeneity of their size distribution [1]. Besides, oxidation of metallic cores increases electrical resistance of films [1] and enhances the effect of negative capacitance at room temperature [2], which is favorable for designing new electronic devices for high-frequency applications. This is particularly important for current efforts towards elaboration of planar noncoil-like inductances fully compatible with microelectronic silicon planar technology. Technologically, "core-shell" NPs, for example, in $\mathrm{Al}_{2} \mathrm{O}_{3}$ matrix could be quite easily sintered by ion-beam sputtering of films in mixed $\mathrm{Ar}+\mathrm{O}_{2}$ atmosphere [1]. There also appears to be a relationship between the chemical composition of insulating matrix (I) in films and agglomeration of metallic NPs inside this matrix [3]. Consequently, this presumes that the formation of NPs with "core-shell" structure also depends on matrix material because it governs efficiency and kinetics of NPs oxidation.

This paper is focused on the comparative analysis of the nearest neighbor environments of $\mathrm{Fe}, \mathrm{Co}$, and $\mathrm{Zr}$ atoms in NPs embedded into $\mathrm{Al}_{2} \mathrm{O}_{3}$ and $\mathrm{Pb}(\mathrm{ZrTi}) \mathrm{O}_{3}$ (PZT) matrixes in order to elucidate the impact of matrix on the formation of NPs with "core-shell" structure.

\section{Experimental}

The films $(\mathrm{FeCoZr})_{x}(\mathrm{I})_{100-x}(31 \leq x \leq 64$ at.\%), where $\mathrm{I}=\mathrm{Al}_{2} \mathrm{O}_{3}$ or PZT were deposited by dc ion sputtering in mixed $\mathrm{Ar}+\mathrm{O}$ atmosphere $\left(P_{\mathrm{O}}=4.2 \times 10^{-3} \mathrm{~Pa}\right.$ and $3.7 \times 10^{-3} \mathrm{~Pa}$ for $\mathrm{I}=\mathrm{Al}_{2} \mathrm{O}_{3}$ and $\mathrm{Pb}(\mathrm{ZrTi}) \mathrm{O}_{3}$, respectively) to a thickness $1-4 \mu \mathrm{m}$ onto $\mathrm{Al}$ substrate. Sputtering targets were composed of $\mathrm{Fe}_{45} \mathrm{Co}_{45} \mathrm{Zr}_{10}$ alloy plates, covered with strips of insulator $\left(\mathrm{Al}_{2} \mathrm{O}_{3}\right.$ and $\left.\mathrm{PbZrTiO}_{3}\right)$ that were located on top. Details of deposition experiment are considered in [4].
X-ray diffraction (XRD) patterns are collected with an Empyrean PANalytical diffractometer using a diffracted beam graphite monochromator and an X'Celerator linear detector $\left(\mathrm{Cu} K_{\alpha}\right.$ radiation) at the grazing incidence of 5 degree with respect to the sample surface. The data obtained were analyzed using the profile fitting program FullProf. X-ray absorption spectroscopy in the extended $\mathrm{X}$-ray absorption fine structure (EXAFS) range measurements are performed at beam line ID26 of the European Synchrotron Radiation Facility using high-energy resolution fluorescence detection (HERFD). The absorption profiles were detected at $\mathrm{Fe}$ and $\mathrm{Co} K$-edges probing intensity of respective $K_{\alpha_{1}}$ fluorescence decay. EXAFS spectra are analyzed using Viper package. The ${ }^{57} \mathrm{Fe}$ transmission Mössbauer spectroscopy measurements are recorded using a conventional constant acceleration type spectrometer with a $40 \mathrm{mCi}{ }^{57} \mathrm{Co}$ in $\mathrm{Rh}$ source at the room temperature.

\section{Results and discussion}

Images of transmission electron microscopy obtained on granular $(\mathrm{FeCoZr})_{x}\left(\mathrm{Al}_{2} \mathrm{O}_{3}\right)_{100-x}$ films and published in [1] confirm that due to the sputtering in $\mathrm{Ar}+\mathrm{O}$ atmosphere "core-shell" NPs are formed. This is additionally supported by magnetometry and Mössbauer spectroscopy evidencing superparamagnetic state of NPs, i.e. absence of their agglomeration at $x \leq 59$. The refinement of XRD patterns for $(\mathrm{FeCoZr})_{x}\left(\mathrm{Al}_{2} \mathrm{O}_{3}\right)_{100-x}$ (see Fig. 1 and also XRD patterns in [1]) shows that at $x \leq 56$ films contain $\alpha$ - $\mathrm{FeCo}(\mathrm{Zr}, \mathrm{O})$ phase (lattice parameter $a=0.286(1)$ ) assigned to non-oxidized crystalline core and amorphous oxides that correspond to shell of NPs. The latter is visible as a hump at $2 \Theta \approx 33$ degrees on the XRD pattern which could be identified either as magnetite $\mathrm{Fe}_{3} \mathrm{O}_{4}$ or/and ferrite $\mathrm{CoFe}_{2} \mathrm{O}_{4}$ although full coincidence is not seen. Contrary, analysis of phase composition of $(\mathrm{FeCoZr})_{56}(\mathrm{PZT})_{44}$ film reveals full oxidation of NPs at even slightly lower $P_{\mathrm{O}}$ (see Fig. 1). It is noteworthy that similar phase composition indicating fully oxidized NPs is observed on XRD patterns 


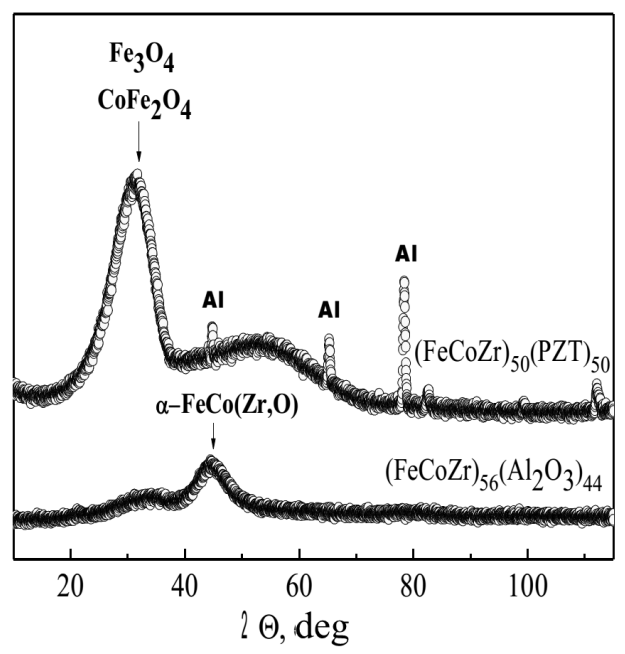

Fig. 1. Selected XRD patterns of (FeCoZr $)-I$ films sintered in $\mathrm{Ar}+\mathrm{O}$ atmosphere.

of films $(\mathrm{FeCoZr})_{x}(\mathrm{PZT})_{100-x}$ for all studied $x$ values $(31 \leq x \leq 64$ at. $\%)$.

Analysis of EXAFS spectra provides deeper insight into the local coordination of Fe and Co ions in NPs. The Fourier transforms of fine structure oscillations extracted from post-edge spectra are shown in Fig. 2. Basing on the comparison of EXAFS oscillations for $\mathrm{Fe}$ and $\mathrm{Co}$ in $(\mathrm{FeCoZr})_{x}\left(\mathrm{Al}_{2} \mathrm{O}_{3}\right)_{100-x}$ films where local environment is predominantly oxide-like for $\mathrm{Fe}$ and bcc metal-like for Co, selective oxidation of NPs was reported earlier [1]. At the same time, maxima of oscillations with the highest intensity for $\mathrm{Fe}$ and $\mathrm{Co}$ in $(\mathrm{FeCoZr})_{x}(\mathrm{PZT})_{100-x}$ films reveal that local coordination is rather oxide-like in both cases. This observation well correlates with XRD results evidencing no visible contribution of non-oxidized $\alpha$ - $\mathrm{FeCo}(\mathrm{Zr}, \mathrm{O})$ cores when NPs are embedded into PZT matrix. It is noteworthy that generally $\mathrm{Zr}$ is found to be in fully oxidized state both in $\mathrm{Al}_{2} \mathrm{O}_{3}$ and PZT matrixes that is assigned to the highest $\mathrm{Zr}$ affinity to oxygen as compared to $\mathrm{Fe}$ and Co.

The Mössbauer spectra of $(\mathrm{FeCoZr})_{x}\left(\mathrm{Al}_{2} \mathrm{O}_{3}\right)_{100-x}$ and $(\mathrm{FeCoZr})_{x}(\mathrm{PZT})_{100-x}$ films, sintered in $\mathrm{Ar}+\mathrm{O}$ atmosphere are presented in Fig. 3. They well illustrate the change of local $\mathrm{Fe}$ states with varying $x$ and due to sequential oxidation of NPs. Fitting of the spectra of $(\mathrm{FeCoZr})_{x}\left(\mathrm{Al}_{2} \mathrm{O}_{3}\right)_{100-x}$ films shows domination of oxide fractions $\mathrm{Fe}^{2+}(\delta \approx 0.95 \mathrm{~mm} / \mathrm{s}, \Delta \approx 1.8 \mathrm{~mm} / \mathrm{s})$ and $\mathrm{Fe}^{3+}(\delta \approx 0.4 \mathrm{~mm} / \mathrm{s}, \Delta \approx 0.9 \mathrm{~mm} / \mathrm{s})$. Basing on XRD results $\mathrm{Fe}^{2+}$ oxide is assigned to $\left(\mathrm{Fe}_{x} \mathrm{Co}_{1-x}\right)_{1-\delta} \mathrm{O}$ phase [1]. At the same time on spectra for films with $x \leq 54$ contribution up to $20 \%$ of $\alpha-\mathrm{FeCo}(\mathrm{Zr}, \mathrm{O})$ cores with $\delta \approx 0.10 \mathrm{~mm} / \mathrm{s}$ and $\Delta \approx 0.4 \mathrm{~mm} / \mathrm{s}$ could be extracted that well correlates with XRD results. Complimentary consideration of the Mössbauer spectroscopy and XRD results with the selective oxidation of $\mathrm{Fe}$ and Co indicated by EXAFS [1] shows that for $x \leq 56$ the metallic core constitutes $\alpha-\mathrm{FeCo}(\mathrm{Zr}, \mathrm{O})$, possibly enriched

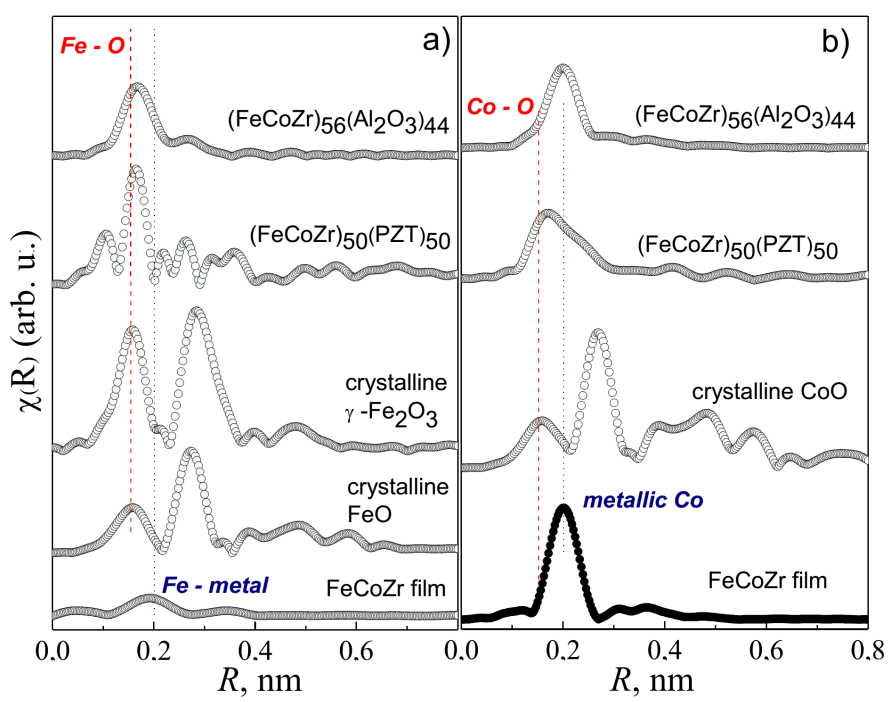

Fig. 2. Fourier transform of the EXAFS oscillations extracted from $\mathrm{Fe}$ (a) and Co (b) $K$-edge spectra. First maxima corresponding to metal (M-M) and oxide $(\mathrm{M}-\mathrm{O})$ local environment are marked with solid and dashed lines, respectively. Spectra are shifted vertically for clarity.

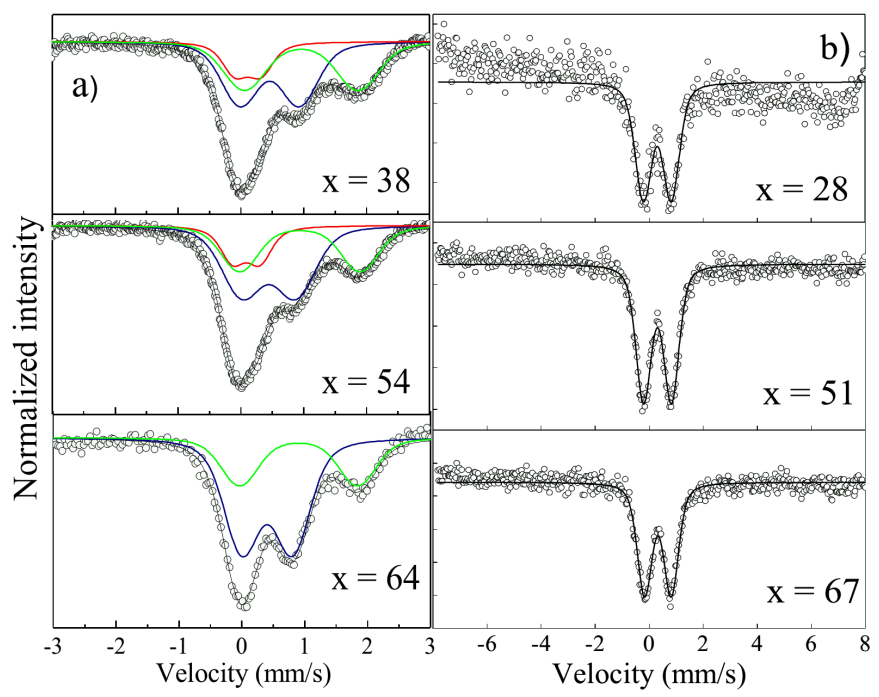

Fig. 3. The fitted ${ }^{57} \mathrm{Fe}$ Mössbauer spectra of $(\mathrm{FeCoZr})_{x}\left(\mathrm{Al}_{2} \mathrm{O}_{3}\right)_{100-x}$ (a) and $(\mathrm{FeCoZr})_{x}(\mathrm{PZT})_{100-x}$ (b) films at RT. Black lines denote the best fits and the colored lines represent the contributions from the subspectra.

with $\mathrm{Co}$, while oxide shell mainly consists of mixed Fe-rich oxides.

The Mössbauer spectra of $(\mathrm{FeCoZr})_{x}(\mathrm{PZT})_{100-x}$ films are well approximated with only one subspectrum characteristic to $\mathrm{Fe}^{3+}$ oxide $(\delta \approx 0.3 \mathrm{~mm} / \mathrm{s}, \Delta \approx 1.0 \mathrm{~mm} / \mathrm{s})$. In so doing, the Mössbauer spectroscopy analysis of local Fe surrounding in NPs embedded into $\mathrm{Al}_{2} \mathrm{O}_{3}$ and PZT matrixes confirms much more pronounced oxidation of NPs in the latter case, which strongly supports XRD 
and EXAFS results. Assuming the difference in chemical stability and oxidation resistance of $\mathrm{Al}_{2} \mathrm{O}_{3}$ and PZT matrixes one could assume that just their chemical properties explain the difference of oxidation efficiency of NPs. Namely, $\mathrm{Al}_{2} \mathrm{O}_{3}$, as opposed to PZT is characterized with very high resistance to oxidation [4]. Thereby immediate encapsulation of $\alpha-\mathrm{FeCo}(\mathrm{Zr}, \mathrm{O}) \mathrm{NPs}$ inside alumina matrix at early stages of deposition at $x<59$ results just in surface oxidation and formation of " $\alpha$ - $\mathrm{FeCo}(\mathrm{Zr}, \mathrm{O})$ coreshell" NPs while further oxidation is decelerated. At the same time, full oxidation of NPs embedded into PZT matrix is unfavorable for the formation of " $\alpha-\mathrm{FeCo}(\mathrm{Zr}, \mathrm{O})$ core-oxide shell" NPs.

\section{Conclusions}

For the first time comparative analysis of local atomic order in $\alpha$-FeCo( $\mathrm{Zr}, \mathrm{O})$ NPs embedded into two different matrixes - $\mathrm{Al}_{2} \mathrm{O}_{3}$ and $\mathrm{PZT}$, reveal crucial role of their chemical inertness and resistance to oxidation in the formation of "metal core-oxide shell" structure. Taking account of TEM images of "coreshell" NPs in $(\mathrm{FeCoZr})_{x}\left(\mathrm{Al}_{2} \mathrm{O}_{3}\right)_{100-x}$ films, non-oxidized $\alpha-\mathrm{FeCo}(\mathrm{Zr}, \mathrm{O})$ contribution in the refined XRD patterns and fitted Mössbauer spectra as well as purely metallic Co surrounding definitely reveal that cores contain Co-enriched metallic alloy surrounded by amorphous $\mathrm{Fe}^{2+}$, $\mathrm{Fe}^{3+}$-oxide shells. Phase composition and local $\mathrm{Fe}$ and $\mathrm{Co}$ states in NPs embedded into PZT matrix evidences full oxidation of NPs and "metal core-oxide shell" structure is not formed. In so doing, chemical inertness and corrosion resistance of $\mathrm{Al}_{2} \mathrm{O}_{3}$ makes it more advantageous for synthesis of stabilized nanocomposite granular films for high-frequency applications.

\section{Acknowledgments}

Author acknowledges the support from the Belarusian State program "Functional materials", project 1.37, the Polish Ministry of Science and Higher Education. Hasylab/DESY (Hamburg) is also acknowledged for the provision of beam time and financial support within the initiative "ELISA: EU Support of Access to Synchrotrons/ FELs in Europe". Special gratitude to Prof. Cz. Kapusta, Prof. J. Zukrowski, Dr. Hab. J. Przewoznik and Dr. Hab. M. Sikora (AGH University of Science and Technology, Faculty of Physics and Applied Computer Science, Department of Solid State Physics, Kraków, Poland) for accomplishment and discussion of XRD, VSM, X-ray absorption and Mössbauer spectroscopies results.

\section{References}

[1] J. Fedotova, J. Przewoznik, Cz. Kapusta, M. Milosavljević, J. Kasiuk, J. Zukrowski, M. Sikora, A. Maximenko, D. Szepietowska, K.P. Homewood, J. Phys. D 44, 495001 (2011).

[2] T.N. Koltunowicz, J. Fedotova, P. Zhukowski, A. Saad, A. Fedotov, J.V. Kasiuk, A.V. Larkin, J. Phys. D 46, 125304 (2013).

[3] J.V. Kasiuk, J.A. Fedotova, M. Marszalek, A. Karczmarska, M. Mitura-Nowak, Yu.E. Kalinin, A.V. Sitnikov, Phys. Solid State 54, 178 (2012).

[4] J. Fedotova, G. Bonnet, F. Pedraza, J. Balmain, S. Dubois, V. Gauthier, M.F. Denanot, N. Ouabadi, A. Letsko, A. Ilyuschenko, A. Akimov, Corr. Sci. 50, 1693 (2008). 